\title{
Unemployment in an Underserviced Specialty?: The Need for Co-ordinated Workforce Planning in Canadian Neurosurgery
}

\author{
S.I. Woodrow, C. O’Kelly, S.J. Hamstra, M.C. Wallace
}

\begin{abstract}
Background: A recent report suggested that newly trained Canadian neurosurgeons are experiencing difficulty finding employment in Canada. Such occurrences, in combination with recent certification restrictions imposed in the US, have resulted in increasing concern that we will shortly be seeing a surplus of graduating neurosurgeons in Canada. The purpose of this study was to develop a better understanding of training and employment patterns in the Canadian neurosurgical workforce. Methods: Using a database provided by the Royal College of Physicians and Surgeons of Canada, the current practice location of recent (1990-2002) neurosurgical certificants and a list of all neurosurgeons practicing in Canada were generated. From these data the number of surgeons per 100,000 patient population, and the number of residents required to maintain this workforce were determined. Results: Practice location could be identified for 183/189 individuals who passed their qualifying examination in neurosurgery during this time. Only $45 \%$ of them are currently practicing in Canada. The current service ratio for this specialty is 0.65 per 100,000 population overall. Although 14.6 residents/ year are being trained, only 6.5/ year are required to maintain the existing neurosurgical workforce. Conclusions: Our data supports the concern about an imminent employment crisis for young neurosurgeons in Canada with more than twice the required number of residents being trained. However, this shortfall of staff positions is at a time when the specialty may be underservicing the country's population. These results highlight the necessity for more cohesive workforce planning in Canada, and in particular, ensuring the appropriate balance between training and need.
\end{abstract}

RÉSUMÉ: Chômage dans une spécialité insuffisamment desservie?: nécessité d’une planification coordonnée de la main-d'œuvre neurochirurgicale au Canada. Contexte: Selon un compte rendu récent, les nouveaux diplômés en neurochirurgie au Canada ont de la difficulté à y trouver de l'emploi. Un tel état de fait, associé à des restrictions concernant la certification imposées aux États-Unis, ont donné lieu à des inquiétudes quant à la possibilité qu'on se retrouve bientôt devant un surplus de nouveaux gradués en neurochirurgie au Canada. Le but de cette étude était de mieux comprendre la dynamique de la formation et de l'emploi de la main-d'œuvre neurochirurgicale au Canada. Méthodes: Le lieu de pratique actuel des neurochirurgiens diplômés entre 1990 et 2002 ainsi qu'une liste de tous les neurochirurgiens pratiquant au Canada ont été extraits d'une base de données fournie par le Collège royal des médecins et chirurgiens du Canada. Le nombre de chirurgiens par 100000 de population et le nombre de résidents requis pour maintenir cette main-d'œuvre ont été déterminés à partir de ces données. Résultats: Il a été possible de déterminer le lieu de pratique de 183 individus sur 189 qui ont réussi leur examen de spécialité en neurochirurgie pendant cette période. Seulement $45 \%$ d'entre eux pratiquent actuellement au Canada. Le nombre de neurochirurgiens par 100000 de population est de 0,65. Bien que 14,6 résidents/année soient formés, il n'en faut que 6,5/année pour maintenir la main d'œuvre neurochirurgicale existante. Conclusions: Nos données mettent en évidence une situation préoccupante concernant l'imminence d'une crise dans la situation de l'emploi pour les jeunes neurochirurgiens au Canada, étant donné que plus du double du nombre de résidents requis est présentement en formation. Cependant, cette pénurie d'emploi est constatée à un moment où la population est insuffisamment desservie par cette spécialité. Ces résultats soulignent la nécessité d'une planification plus concertée de la main d'œuvre au Canada, spécialement en ce qui concerne l'équilibre entre la formation et les besoins.

Can. J. Neurol. Sci. 2006; 33: 170-174

The primary function of the medical education system is to provide training for adequate numbers and types of physicians to meet the needs of society. For highly specialized fields such as neurosurgery this requires a minimum of six years of training following medical school at a cost of over 1.5 million dollars per surgeon to taxpayers. ${ }^{1}$ Despite this investment, neurosurgery has traditionally experienced a high emigration rate of Canadian trained graduates with almost half relocating to the United States (US). ${ }^{2}$ It has been suggested that this "brain drain" occurred
From the Department of Surgery (SIW, COK, SJH, MCW), Wilson Centre for Research in Education, Faculty of Medicine (SIW, SJH), University of Toronto, Toronto, ON; Department of Medical Education, University of Michigan (SJH), Ann Arbor, Michigan, USA.

Received August 5, 2005. Accepted in final Form November 18, 2005. Reprint requests to: M.C. Wallace, Division of Neurosurgery, University Health Network - Western Division, 399 Bathurst St., West Wing 4-450, Toronto, Ontario, Canada, M5T 2S8. 
because of more lucrative salaries, a greater diversity of practices and better operating room resources. ${ }^{2}$ Three young neurosurgeons recently challenged this view by claiming that they were forced to take positions in the US because of lack of employment opportunities in Canada. ${ }^{3}$ Indeed, there is now a growing concern in the Canadian neurosurgical community that trainees may face a job shortage upon graduation. ${ }^{4}$ Adding to this is the 1997 decision of the American Board of Neurological Surgeons (ABNS) to rescind their recognition of Canadian neurosurgical training programs thereby minimizing the ability of recent neurosurgery graduates to practice in the US. ${ }^{5}$

We analyzed employment patterns of Canadian neurosurgeons including recent Canadian neurosurgical graduates. We further analyzed the number of trainees required to sustain the delivery of neurosurgical care in Canada. These findings are discussed in the context of Canadian medical workforce policy.

\section{Methods}

The study was approved by the Ethics Review Board at the University of Toronto.

Using data provided by the Royal College of Physicians and Surgeons of Canada (RCPSC) and the Canadian Medical Directory (2004), ${ }^{6}$ lists were generated identifying the location of all currently practicing Canadian neurosurgeons and recently certified (1990-2002) Fellows of the Royal College of Physicians and Surgeons of Canada $(\mathrm{FRCS}(\mathrm{C}))$ in neurosurgery. The list included both individuals who graduated from Canadian medical schools and foreign medical graduates (FMGs). The data was cross-referenced with association membership listings,

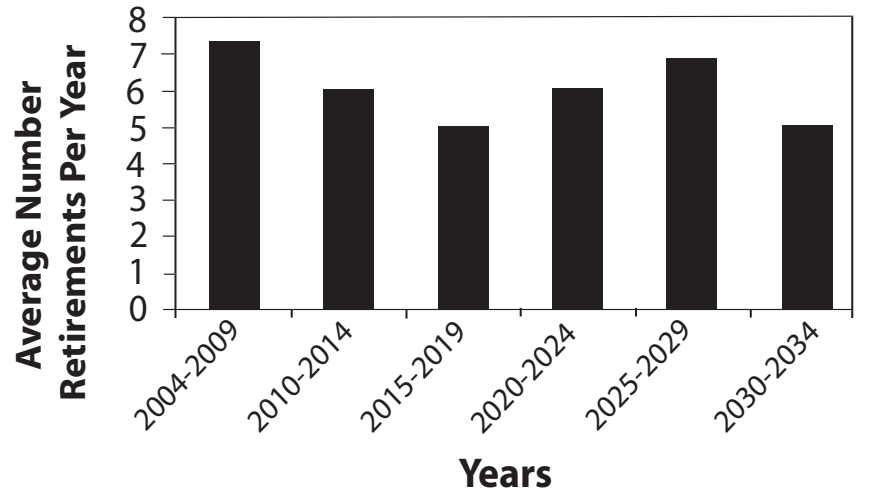

Figure 2: Predicted Annual Retirement Rates. Assuming a 30-year career span the annual retirement rates for the current Canadian neurosurgical workforce were determined across five year intervals. Although a slightly larger number of retirements will likely occur in the upcoming few years (7.3 surgeons/year) this rate will decrease slightly over the following decade.

provincial colleges' and hospital websites, personal knowledge and telephone confirmation to generate a final listing.

In February 2004, a list of all neurosurgical residents in Canada was generated from the Young Neurosurgeon's Directory. ${ }^{7}$ The list was further refined by contacting a resident representative in each training program. From these data, the number of Canadian and non-Canadian (i.e. foreign-sponsored FMGs) residents trained per year was determined. Data regarding matched training positions in neurosurgery was obtained from the Canadian Resident Matching Service (CaRMS) for the years 1993-2003. ${ }^{8}$

Combining these data with Canadian population data, ${ }^{9}$ the number of practicing neurosurgeons per 100,000 population was calculated for each province. In addition, based on data available in Ontario regarding the mean age of neurosurgeons at the time of RCPSC certification ${ }^{10}$ and given a standard retirement age of 65, a 30-year career span was used to calculate the number of neurosurgeons expected to retire over upcoming 5-year intervals from the RCPSC data, assuming a flat distributions of individuals. Finally, the average number of residents required to sustain the current ratio of neurosurgeon to population was estimated. Assuming 7-years of postgraduate training are required to become a certified neurosurgeon in Canada, the number of residents anticipated to graduate yearly was calculated from the number currently in training.

\section{RESUltS}

\section{Workforce Analysis}

According to RCPSC data, in the spring of 2004, 198 neurosurgeons were practicing in 


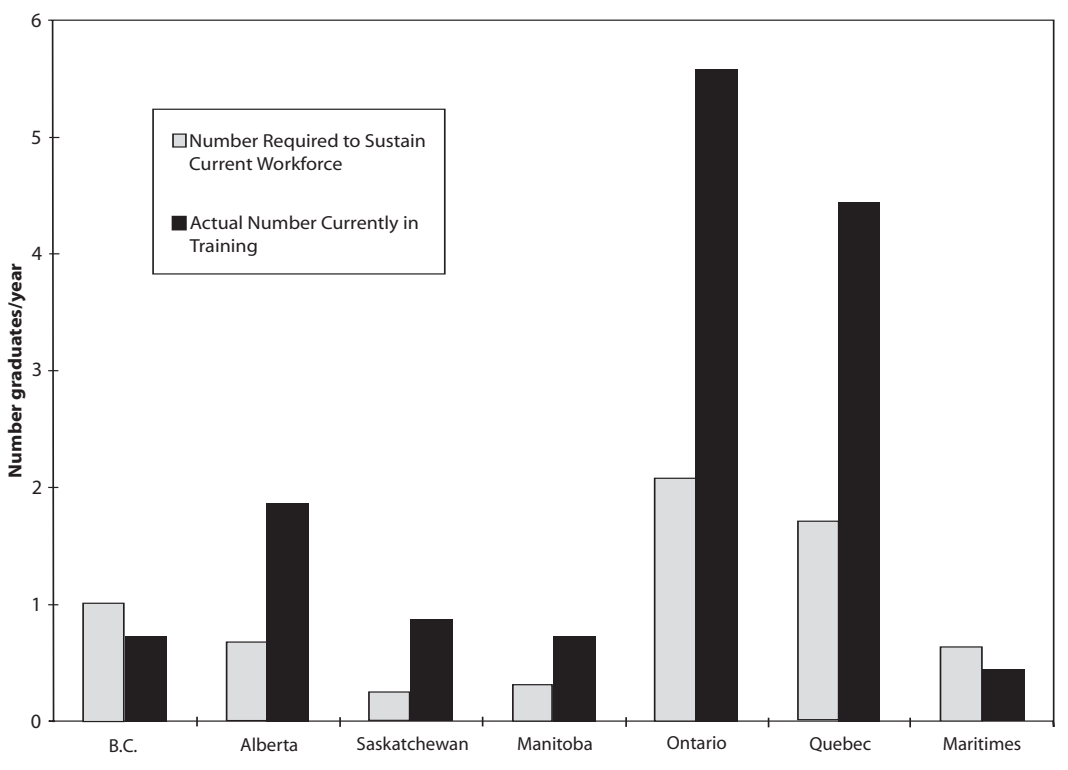

Figure 3: Distribution of Neurosurgical Residents Across Canada. The number of neurosurgery residents required to graduate per year to maintain the current population of staff surgeons in individual provinces is plotted next to the actual number of trainees (not including FMGs) that will be completing their training over the next seven years. Overall, a two-fold excess of residents appears to be in training.
Canada resulting in a service ratio of 0.63 per 100,000 patient population overall (Figure 1). Only Manitoba and the Maritime provinces have approached the benchmark 1:129,450 recommended by the RCPSC ${ }^{11}$ which translates into 0.77 per 100,000 population. Ontario has the lowest service ratio of 0.51 per 100,000 population.

Projected yearly retirement rates range from 7.3 (2004-2009) to 5 (2015-2019) requiring an average of 6.6 newly certified neurosurgeons per year to maintain the current physician-topopulation ratio nationally (Figure 2). The replacement rates for individual provinces are displayed graphically in Figure 3. Excluding FMGs, Canada was training 102 neurosurgical residents in 2004. Extrapolating these numbers, this will produce an average of 14.6 graduates per year completing their training. The majority of provinces are training more than twofold the number of neurosurgeons required.

One hundred and eighty nine neurosurgeons obtained their FRCS(C) certification between 1990 and 2002 (Table 1). Three are no longer in practice. Of the remainder, current practice location was confirmed for 183/ 186 (98\%). Only 45\% (87/183) of all recent certificants are practicing neurosurgery in Canada. Examining specifically the graduates of Canadian medical schools only 55\% (73/132) are currently practicing in Canada. The proportion of certificants from each year practicing in the US has remained stable over the 13-year time period examined (data not shown). Although most Americans trainees returned to the US, a significant proportion (30/43) of FMGs from other countries continue to practice in North America.

From 1993 - 2003, CaRMS matched 140 trainees to provincially funded neurosurgical positions in Canada - an average of 12.7 positions per year. Including FMGs whose postgraduate training was supported through non-Canadian funding, this has resulted in an annual average of 14.5 individuals attaining their certification in neurosurgery. Over the last ten years, there has been a slight increase in the number of individuals entering and completing neurosurgical training
(Table 2). The number of FMGs acquiring RCPSC certification, however, has remained stable throughout this time period (data not shown).

\section{Discussion}

This study analyzed recent trends in the training and employment of neurosurgeons in Canada. Our results indicate we are training over twofold the number of Canadian - funded residents given the size of the current neurosurgical workforce in this country, a finding that supports an earlier published prediction. ${ }^{12}$ Contributing to this imbalance is the steady increase in the number of individuals entering and graduating from neurosurgical residency (Table 2). Although historically over $40 \%$ of recent Canadian graduates have emigrated to the US (Table 1), the ABNS ruling may limit this practice resulting in a

Table 1: Current Practice Location of Recent Neurosurgical Certificants

\begin{tabular}{lcccc}
\hline \multicolumn{4}{c}{ Current Practice Location } \\
\hline $\begin{array}{l}\text { Undergraduate } \\
\text { Medical School }\end{array}$ & Canada & U.S.A. & Other & Fellowship \\
\hline Canada & 73 & 52 & 2 & 5 \\
USA & & 5 & 1 & \\
FMG & 14 & 16 & 13 & 2 \\
TOTAL & 87 & 73 & 16 & 7 \\
\hline
\end{tabular}

The current practice location of recent neurosurgical certificants of the RCPSC (1990-2002) is shown based on individuals' location of undergraduate medical training (Canada, USA, or outside North America (FMG). Also included are individuals who were undertaking fellowships. 
Table 2: Number of Individuals Training in Neurosurgery in Canada

\begin{tabular}{ccc}
\hline Year & $\begin{array}{c}\text { CaRMS Positions } \\
\text { Matched }\end{array}$ & $\begin{array}{c}\text { RCPSC } \\
\text { Certificants }\end{array}$ \\
1993 & 7 & 13 \\
1994 & 13 & 12 \\
1995 & 11 & 14 \\
1996 & 14 & 20 \\
1997 & 12 & 16 \\
1998 & 12 & 19 \\
1999 & 13 & 8 \\
2000 & 13 & 18 \\
2001 & 12 & 20 \\
2002 & 16 & 15 \\
2003 & 17 & 21 \\
2004 & 15 & 20 \\
\hline
\end{tabular}

The number of successful RCPSC certificants and the number of Canadian medical students who matched to provincially-funded residency positions in neurosurgery overall each year is shown.

greater surplus of newly qualified surgeons with limited opportunities for employment. Moreover, the relatively stable retirement rates predicted by our data (Figure 2) suggest that this mismatch will not improve in the upcoming years.

From a recruiting and training perspective, if these disparities persist they can only negatively impact the future of neurosurgery in Canada: decreased morale among current trainees who invest up to 15 years in higher education may lead to increased attrition. Ultimately, bright and talented medical students may be dissuaded from entering the profession. Data from other specialties suggest that this group is attuned to the marketplace of prospective career choices. ${ }^{13}$ The small size of the 2005 CaRMS application pool for neurosurgical residency positions ${ }^{8}$ underscores this concern. At a time when "lifestylespecialties" are increasing in popularity,${ }^{14}$ it would serve the neurosurgical specialty well to acknowledge these potential threats and work to address them.

One of the intrinsic difficulties in this area of healthcare resource planning is our limited ability to forecast the healthcare needs of the population. Traditionally, a number of different approaches, including benchmarking, needs-based, demandbased and dynamic modeling, have been used to predict workforce requirements in healthcare ${ }^{15}$ Such methods, however, are limited by their reliance on historical data as well as their inability to account for the variation in need within a population. In addition, technological advances, increased subspecialization and changing practice patterns amongst the current generation of physicians, including the emergence of surgeon-scientists, represent additional confounding factors. ${ }^{16,17}$ Consequently numerous countries, like Canada, are struggling to manage their neurosurgical workforces. ${ }^{18-20}$

The limitations of such modeling is demonstrated no better than in Canadian neurosurgery itself where less than ten years ago it was predicted that there would shortly be a shortage of specialists in this field. ${ }^{2}$ As a result, the current ideal neurosurgeon-to-population ratio for Canada remains unclear. While international neurosurgical workforces in the western world range from $0.26: 100,000$ (United Kingdom) to 1:100,000 (US), ${ }^{19,20}$ a recent RCPSC report recommended one of $0.77: 100,000 .{ }^{11}$ Using the RCPSC figure as a target, our data suggest that neurosurgical services are lacking in six out of eight regions of the country, corroborating the findings of previously published reports. ${ }^{2,21}$ More recently, a task force investigating the status of Ontario's neursurgical services documented a high burden of work placed upon neurosurgeons in the province with the smallest per capita workforce: the report's authors concluded by questioning the sustainability of the current system and expressed a clear need to expand the current number of surgeons. ${ }^{22}$

One obvious short-term solution may be to use the excess of upcoming graduates to alleviate the apparent shortage identified in most parts of the country. Unfortunately, creating new neurosurgical positions is a complex process, requiring a significant investment of resources including necessary diagnostic and operating room equipment, and allied healthcare workers to provide an infrastructure for highly specialized patient care. It is this global cost, requiring multiple levels of financial commitment, that may be one obstacle to the imminent hiring of additional neurosurgical staff in many provinces. Provinces in which alternate funding plans have been established (e.g. Maritimes, Manitoba, British Columbia) may be closer to this target, having negotiated local neurosurgical workforce sizes independent of these other resources.

Even with a better understanding of workforce requirements in Canada, regulating the input of physicians into the system is inherently difficult, primarily owing to the control of both education and healthcare at the provincial level. In addition, decisions regarding postgraduate positions are invariably made at the institutional level where interests may also be divided. With no large-scale co-ordination of resources, local requirements, such as the need for increasing resident numbers in the face of decreasing resident work hours, likely prevail over other provincial or national interests. Such a practice raises ethical concerns regarding the use of trainees to fulfill service requirements at the expense of reasonable prospects for employment. A similar concern may be voiced regarding FMGs who are sponsored by foreign governments but of whom $70 \%$ remain in North America upon completion of their training. At a time when there is an overall shortage of physicians in this country, graduating an excess seven Canadian neurosurgeons per year represents a loss of over $\$ 10$ million $^{1}$ in resources for taxpayers that may be better allocated elsewhere.

\section{Limitations}

As a database analysis, this study comments on the recent trends in location of employment for Canadian neurosurgical graduates. We recognize the fluid nature of the workforce with potential for constant regional, national and trans-national movement and hence inaccuracy with data collection. The analysis of provincial neurosurgeon-to-population ratios may represent an oversimplification. Regional differences in access to care within each province may necessitate variable numbers of neurosurgeons. For example, maintenance of adequate 
neurosurgical coverage in remote centers may require an inflated service ratio. Moreover, in determining the number of trainees required to sustain the current population we assumed a 30-year career span and a 7-year (6 year residency plus 1 year fellowship) training program. These are conservative approximations that, if anything, underestimate the size of the discrepancy between input (i.e. number of residents) and need. Finally, this study presents the current situation in the Canadian neurosurgical workforce. In order to accurately regulate this workforce future studies modeling the complex interplay of resident supply, regional demands, changing healthcare needs and flow of personnel are required.

\section{RECOMMENDATIONS}

Beyond the speculations of previously published reports, this study provides data supporting the existence of an imminent employment crisis in Canadian neurosurgery through the training of an excess of residents given the size of the current workforce. With the impending effects of the ABNS ruling, this situation is set to deteriorate further and interventions at multiple levels are needed to help alleviate it. For example, creation of more staff positions will help to provide the Canadian population with better neurosurgical services while temporarily alleviating the employment shortfall. First, however, a more current review of the specialty needs of the Canadian population, such as has recently been done in Ontario, ${ }^{22}$ is required - one that will incorporate local variations with the changes in healthcare practice. In the short term, negotiations with the licensing bodies in other countries, such as the ABNS, will also provide an outlet for current trainees; however, this remains a suboptimal solution both economically and ethically. Ultimately, a reduction in resident numbers may be required. At the very least, these numbers should be co-ordinated with employment positions to allow for better workforce planning. Through pre-existing professional organizations such as the Canadian Neurosurgical Society, and the availability of computer networks, consistent monitoring of such positions can be more easily accomplished than in the past. However, the regulation of training positions may itself prove a far more complex task - one that is going to require the commitment of all training programs across the country in order to ensure effective management.

Clearly, the phenomenon we describe in neurosurgery is a symptom of the broader problem of a lack of national policy for healthcare human resources in Canada. Although now recognized as a priority in healthcare, movement towards resolution of this issue may be hindered by jurisdictional conflicts between multiple stakeholders with competing interests. In order to rise to our responsibility to the Canadian public, we must improve the approach to workforce planning in this country. It is an issue with which all provinces must contend that can best be addressed with a cohesive approach governed by strong leadership at the national level. It is time for Canadian neurosurgeons to take control of their profession to ensure a secure and successful future.

\section{ACKNOWLEDGEMENTS}

Dr. Woodrow is supported by a Royal College of Physicians and Surgeons of Canada Fellowship in Medical Education. Dr.
O'Kelly is supported by a Heart and Stroke Foundation of Canada Research Fellowship.

The authors thank Drs. Joshua Tepper, Glenn Regehr and Brian Hodges for their advice during manuscript preparation.

\section{REFERENCES}

1. Valberg LS, Gonyea MA, Sinclair DG, Wade J. Planning the future academic medical centre. CMAJ. 1994;151(11):1581-7.

2. Hugenholtz H. Neurosurgery workforce in Canada, 1996 to 2011. Canadian Neurosurgical Society. CMAJ. 1996;155(1):39-48.

3. Kondro W. New neurosurgeons left jobless: where's the plan? CMAJ. 2004;170(9):1377-8.

4. Findlay JM. Manpower in the Canadian neurosurgical workforce: is a crisis looming? Can J Neurol Sci. 2004;31(2):138.

5. American Board of Neurological Surgeons. Available from: http://www.abns.org/certification.html\#1c. Website accessed May 282005.

6. Canadian Medical Directory 2004. Available from: http://www.mdselect.com. Accessed March 5, 2004.

7. Young Neurosurgeons' Society. Young Neurosurgeons' Directory 2003-2004 Edition. Congress of Neurological Surgeons, 2003.

8. Canadian Residency Matching Service (CaRMS). Available from: http://www.carms.ca/jsp/main.jsp. Website accessed July 25, 2005 .

9. Statistics Canada. Provinces and territories population data, 2003. Available from: http://www statcan ca/english/Pgdb/demo02htm. Accessed May 282005.

10. Ontario College of Physicians and Surgeons - Doctor Search Site. Available from: http://www.cpso.on.ca/. Website accessed March 14, 2004.

11. Royal College of Physicians and Surgeons of Canada. National Specialty Physician Review. Ottawa: 1988.

12. Desbiens R, Elleker MG, Goldsand G, Hugenholtz H, Puddester D, Toyota B, et al. Current educational issues in the clinical neurosciences. Can J Neurol Sci. 2001;28(4):299-308.

13. Anzilotti K, Kamin DS, Sunshine JH, Forman HP. Relative attractiveness of diagnostic radiology: assessment with data from the National Residency Matching Program and comparison with the strength of the job market. Radiology. 2001;221(1):87-91.

14. Dorsey ER, Jarjoura D, Rutecki GW. Influence of controllable lifestyle on recent trends in specialty choice by US medical students. JAMA. 2003;290(9):1173-8.

15. Joyce CM, McNeil JJ, Stoelwinder JU. Time for a new approach to medical workforce planning. Med J Aust. 2004;180(7):343-6.

16. Martini CJ. Medical workforce planning and medical education. Attaining consensus. JAMA. 1993;270(9):1101-4.

17. Blumenthal D. New steam from an old cauldron--the physiciansupply debate. N Engl J Med 2004; 350(17):1780-7.

18. Australian Medical Workforce Advisory Committee. The neurosurgery workforce in Australia: 1999-2010. 2000.

19. Nelson MJ. Safe Neurosurgery 2000. Society of British Neurological Surgeons 2000; Available from: http:// www.sbns.org.uk/sbns/safety_standards_paediatric.htm. Accessed May 28, 2005.

20. Couldwell WT, Gottfried ON, Weiss MH, Popp AJ. Too many? Too few. New study reveals current trends in US neurosurgical workforce. AANS Bulletin 2003; Winter:7-9.

21. Petryshen P, Wallace MC. Recommendations for Improved Access to Neurosurgery in Toronto. Toronto District Health Council 2003; Available from: http://www.dhcarchives.com/protected/ location.asp? ModuleID=3\&Categ ory ID $=137 \&$ lang $=e n$. Accessed May 28, 2005.

22. Tepper J, Jaigobin C, Wang C. Health human resources for neurosurgical services in Ontario. ICES investigative report. Toronto: Institute for Clinical Evaluative Sciences, 2005. Available from: http://www.ices.on.ca/file/HHR_Neurosurgical_ Services_Final2.pdf. Website accessed October 25, 2005. 